\title{
Os estatutos econômicos dos primeiros cristãos: análise das formas literárias em São Mateus 6, 19-34 \\ The early Christians' economic statutes: analysis of literary forms in Saint Matthew 6, 19-34
}

\author{
Anderson de Oliveira Lima*
}

\begin{abstract}
Resumo
Este artigo apresenta uma proposta para a interpretação de Mateus 6, 19-34 a partir da análise das formas. A atenção dada pelo autor às estruturas poéticas dessa unidade textual é aqui destacada para que os textos sejam lidos de acordo com suas próprias exigências estilísticas. Além desses textos, que tratam especificamente do problema econômico dentro do grupo mateano, a estrutura dada pelo autor ao chamado Sermão da Montanha (caps. 5-7) também é abordada como evidência do esmero formal próprio de Mateus. Ao tratar dessa pequena amostra de textos, pretende-se esboçar algumas imagens para compreender socioeconomicamente o grupo de Mateus em seu ambiente urbano na Galileia ao final do século I, cenário que o distinguia dos seguidores de Jesus da primeira geração - camponeses pauperizados que se tornavam profetas itinerantes. Por fim, a exegese nos conduz à hipótese de que, por suas peculiaridades, o grupo mateano é forçado a reler as tradições herdadas sob nova perspectiva, na qual a pobreza é uma opção obrigatória para esse novo e citadino judaísmo cristão.
\end{abstract}

Palavras-chave: Evangelho de Mateus; Exegese; Cristianismo primitivo; Economia; Sermão da Montanha.

\begin{abstract}
This article offers an interpretation of Matthew 6, 19-34 starting from the analysis of forms. The poetic structure of this textual unit is highlighted so that the texts can be read according to their own stylistic framework. Besides that text, which deals specifically with economic problems in Matthew's group, the structure of the Sermon on the Mountain (Mt 5-7) is also evidence of the formal care typical of Matthew. This little sample of texts aims to delineate some images in order to know Matthew's group, in social and economic terms, within the urban environment in Galilee by the end of the $1^{\text {st }}$ century, a milieu that distinguished the group from the first generation of Christians, all of them poor farmers transformed into wandering prophets. Finally, the exegesis leads to the hypothesis that, given its personal characteristics, Matthew's group is forced into a re-reading of Christian traditions in a new perspective, in which poverty is a mandatory option to this new Jewish-Christian urban movement.
\end{abstract}

Keywords: Gospel of Matthew; Exegesis; Primitive Christianity; Economy; Sermon on the Mountain.

Artigo recebido em 30 de setembro de 2009 e aprovado para publicação em 10 de novembro de 2009.

* Bacharel em música (violão erudito) pela Universidade Cruzeiro do Sul (São Paulo, 1999); especialista em Bíblia, com ênfase na tradição profética (2008); mestre em Ciências da Religião (Literatura e Religião no Mundo Bíblico) do Programa de Pós-Graduação em Ciências da Religião da Universidade Metodista de São Paulo. E-mail: aol10@ibest.com.br 


\section{Introdução}

Os estudos produzidos sobre o evangelho de Mateus e o grupo que lhe deu origem já nos legaram valiosas conclusões, a partir das quais é possível distinguir o grupo mateano como um representante citadino do judaísmo cristão do primeiro século. Mas, em geral, a pesquisa ainda está fundamentada nas oposições constatáveis entre o grupo de Mateus e o dos fariseus ou escribas, especialmente no âmbito religioso desse conflito (cf. DUARTE, 2009 , p. 5), embora existam vários outros aspectos pelos quais poderíamos investigar a constituição desse grupo. Nós, por exemplo, temos nos dedicado aos aspectos econômicos do evangelho e, mesmo delimitando assim nosso objeto de estudo, ainda são muitos os caminhos que poderíamos trilhar.

Neste ensaio, escolhemos tratar do aspecto econômico do protocristianismo mateano através da análise das formas de algumas porções do evangelho. Mais especificamente, estudaremos as características estruturais empregadas em Mt 6, 19-34, procurando destacar as ênfases de conteúdo sugeridas pelo próprio arranjo que o evangelista deu a esse conjunto textual. Além da análise das formas, dedicamo-nos previamente à tradução dos textos gregos para apresentar aqui uma versão própria de Mt 6 , 19-34 mais condizente com o tema econômico que permeia esses textos. Alguns detalhes sobre a tradução nos parecem determinantes e por isso serão exibidos no corpo do texto, os demais estarão em notas de rodapé.

Já que admitimos que esta será uma análise parcial dos textos, também temos que admitir o caráter provisório de algumas das conclusões aqui alcançadas. Nosso principal objetivo é demonstrar o valor do emprego da análise das formas como passo essencial para o estudo dos textos bíblicos, em especial para o evangelho de Mateus, e não fazer uma interpretação aprofundada dos textos. Esperamos que nossas sugestões e prévias conclusões sejam aplicadas posteriormente na reconstrução desse grupo cristão que há muito foi soterrado pelo tempo e que nós, cada vez utilizando-nos de diferentes instrumentos, insistimos em escavar. 


\section{Localizando o grupo mateano}

Antes de passarmos ao estudo dos textos, talvez seja útil dedicar alguns parágrafos introdutórios ao evangelho de Mateus, registrando pressupostos que, em seguida, consciente e inconscientemente, delinearão nossas comparações entre os documentos literários e seu grupo de origem. Comecemos, pois, pelas hipóteses que até aqui alcançaram maior consenso.

Atualmente não há grandes debates quanto à hipótese de que o evangelho de Mateus teria surgido a partir da coleção de tradições cristãs mais antigas, dentre as quais se destacam o evangelho de Marcos e a chamada Fonte dos Ditos ou simplesmente Q (KOESTER, 2005, p. 188). Essas tradições teriam sido reunidas sob a forma de um novo evangelho entre as décadas de 80 e 90 d.C. (OVERMAN, 1997, p. 26), datação alcançada principalmente a partir da maneira como o evangelista aplica os dados coletados às circunstâncias próprias do momento em que os diferentes movimentos judaicos se confrontaram em busca de alguma supremacia nas décadas que sucederam a guerra judaica contra os romanos de 66-70 d.C. ( SALDARINI, 2000, p. 186).

Mais controvertida é a questão da localização geográfica do grupo mateano. Grande número de estudiosos que seguem a tradição consideram que o evangelho seja um produto da Síria, ${ }^{1}$ porém um número crescente de pesquisadores tem optado pela Galileia como local de origem de Mateus, ${ }^{2}$ principalmente pela certeza de que tanto o judaísmo formativo como o seu sucessor, o judaísmo rabínico, são fenômenos essencialmente palestinos (OVERMAN, 1997, p. 156). Deveras, dificilmente os inimigos do grupo mateano, os judeus ${ }^{3}$ autoridades de maior influência nas sinagogas locais, podem ser identificados com outro grupo que não este da Palestina.

Também nós acreditamos que o evangelho de Mateus pertença à Galileia, mas consideramos mais relevante situá-lo num ambiente citadino. Em Mateus, estão em

\footnotetext{
${ }^{1}$ Como se vê nos seguintes trabalhos: CARTER, 2002; LUZ, 1993, v. I.

${ }^{2}$ Exemplos de trabalhos que defendem a localização de Mateus na Galileia: GARCIA, 2001; OVERMAN, 1997; STEGEMANN e STEGEMANN, 2004.

3 Anthony J. Saldarini demonstra que a designação "judeus" é pejorativa no evangelho de Mateus e não se aplica a toda a população de Israel. Esta era a maneira como os gentios os chamavam e Mateus aplica-a, exclusivamente, aos seus adversários, os líderes que se opunham ao programa judaico-cristão proposto pelo evangelista (Cf. SALDARINI, 2000, p. 64-67).
} 
destaque personagens essencialmente urbanos, como os coletores de impostos, militares, centuriões, além de muitos escravos e prostitutas (STEGEMANN; STEGEMANN, 2004, p. 261-262). Nesse ambiente, o grupo provavelmente tinha contato diário com pessoas de diferentes etnias e classes sociais, e podemos supor que tal heterogeneidade também caracterizava os próprios componentes do grupo. Nota-se em Mateus que, ao mesmo tempo em que se ambiciona reformar a religião de Israel, quer-se alcançar os gentios; ao mesmo tempo em que se preserva a prática rigorosa da Lei, esta é interpretada segundo padrões de tolerância racial incomuns. Essas são algumas das peculiaridades desse grupo judaicocristão que devemos ter em mente enquanto lemos os textos econômicos de Mateus.

\section{Sermão da Montanha e seus conjuntos literários}

O evangelho de Mateus foi escrito quando, gradualmente, um grupo de judeus que seguiam os ensinos de Jesus ia distanciando-se do grupo judaico majoritário e vendo-se forçado a delinear sua identidade e defender seus pontos de vista. Este era um processo natural, e cada grupo procurava definir suas práticas, seus ensinos, e em especial, seu posicionamento acerca da mais importante instituição da religiosidade judaica: a Lei (GARCIA, 2008, p. 91). O famoso Sermão da Montanha (Mt 5-7) possui exatamente esta função dentro do evangelho: fornece definições para a vida comunitária de um novo grupo dissidente e apresenta a interpretação que esse grupo dá à Lei (OVERMAN, 1997, p. 99 e 104).

Voltado primeiramente aos participantes do grupo mateano, o sermão procura diferenciar os seguidores de Jesus dos fariseus e escribas por meio do incentivo a uma conduta ética superior. Empregando a autoridade de Moisés e a de outros célebres personagens veterotestamentários e aplicando-as a Jesus, ${ }^{4}$ Mateus o faz subir ao monte e de lá proclamar a Lei dos judeus cristãos (Mt 5, 1-2), a fim que eles se vejam como os fiéis praticantes da Torá. Essa referência topográfica é significativa também noutro sentido: a subida ao monte marca o início desse conjunto legislativo cuja moldura se fecha em 7, 28 29, quando Jesus acaba o seu discurso.

\footnotetext{
${ }^{4}$ Veja, por exemplo, Moisés em Êxodo 19, 3; 24, 12-13.18; 34, 2.4; Dt 9, 9; 10, 1.3, depois Abraão em Gn 22, 2.14, e também Elias nos montes Carmelo e Horebe em 1Rs 18, 18-46; 19, 8-18.
} 
O comentarista Ulrich Luz propôs uma polêmica estruturação que apresenta o Sermão da Montanha sob a forma de um grande quiasmo, que traria a oração do Pai Nosso exatamente no ponto central do sermão, atribuindo-lhe grande ênfase (LUZ, 1993, p. 260). A proposta de Luz, todavia, apresenta problemas que não podemos ignorar: Em relação aos textos que aqui vamos estudar, Luz os delimita de maneira estranha $(6,19-7.11)$ e os relaciona a 5, 21-48. Para justificar essa relação, ele utiliza-se de um critério questionável, dizendo que há 56 linhas em cada uma das seções segundo o texto grego, julgando que a extensão aproximada das unidades evidencia essa relação. Mas obviamente não é possível afirmar que o número de linhas encontradas no texto grego que hoje manuseamos corresponda ao número de linhas do texto original de Mateus, que simplesmente não existe. A própria metodologia empregada para a reconstrução dos textos gregos do Novo Testamento exclui a validade desse tipo de comparação formal que Luz, surpreendentemente, emprega.

A insatisfação em relação à proposta de Luz nos levou a buscar uma solução própria para a compreensão da estrutura do Sermão da Montanha. Ao menos até 6,34, é-nos possível compreender a estrutura dada ao sermão pelo autor, que de maneira bem consciente reúne unidades textuais que lhe parecem similares. Logo no início, após a passagem introdutória que localiza Jesus no alto do monte, encontramos duas seções bem delineadas: uma trazendo as famosas "bem-aventuranças" (5,3-12), que apresentam os atributos desejáveis para cada membro do grupo (OVERMAN, 1997, p. 32) e que sugerem padrões formais cuidadosos, ${ }^{5}$ e outra sobre "o sal da terra e a luz do mundo", que estimula um comportamento exemplar diante da sociedade (5, 13-16). Vemos essas duas seções como as mais importantes do sermão, e tudo o que a seguir é dito deve ser entendido a partir delas; ou seja, é por ser um povo especial e por terem que exibir essa especialidade ao mundo que todo o restante do sermão aí está.

Após essa abertura, segue-se um importante conjunto literário em que Jesus revisa alguns dos mandamentos da lei, radicalizando-os em busca de uma perfeita prática da lei divina (5, 17-48). Para identificar esse conjunto, temos uma abertura em que Jesus explica que não veio abolir a Lei, mas cumpri-la, onde também fica claro que estão em pauta as

\footnotetext{
${ }^{5}$ Veja a proposta de estruturação das bem-aventuranças num quiasmo feita por Paulo Roberto Garcia em sua dissertação de mestrado de 1995 (GARCIA, 1995).
} 
discórdias intrajudaicas a respeito da Lei $(5,17-20)$. Em seguida é fácil notar a estrutura mateana através da repetição do refrão: "Ouvistes que foi dito... Porém eu vos digo...”. Essa mesma fórmula é empregada de maneira quase idêntica para atualizar os mandamentos sobre homicídio, adultério, divórcio, juramentos, vingança e amor aos inimigos. Temos aí uma unidade que não pode ser dividida em qualquer delimitação.

Terminada a renovação dos mandamentos, o sermão apresenta outro conjunto literário, desta vez dirigido diretamente ao conflito do grupo mateano com os fariseus (6, 118). O texto questiona as atitudes dos fariseus, acusa-os dizendo que suas práticas religiosas não são sinceras e que suas boas ações são feitas por exibicionismo, tendo como finalidade única a admiração dos homens. Há também uma abertura para esta seção $(6,1)$, e um refrão que se repete em cada subunidade: Primeiro, Jesus descreve a ação dos fariseus como exibicionismo e diz "Verdadeiramente vos digo: eles recebem a recompensa deles". A recompensa dos fariseus é a admiração alheia, a honra na terra, coisas que são negativas principalmente por serem adquiridas a partir de ações religiosas fingidas. Em seguida, Jesus descreve como deve ser a atitude dos seguidores em relação à mesma prática, e conclui dizendo: "E o teu pai que vê secretamente te recompensará". Nessa seção são debatidas as práticas da caridade, da oração e do jejum, e sendo assim, não vemos no Pai Nosso o mesmo destaque que viu Ulrich Luz.

Finalmente chegamos ao texto de nosso interesse, Mt 6, 19-34, que é um agrupamento de textos feito a partir de um tema em comum. Vê-se que, a partir do capítulo 7, o tema muda para o julgamento ao próximo, depois para a persistência na oração, e não se justifica a delimitação de Luz que reuniu Mt 6, 19-7.11.

Sobre o final do Sermão da Montanha, a dificuldade de encontrar uma proposta formal satisfatória se acentua. No capítulo 7, temos unidades de menor extensão e de temas mais variados, ali colocadas por serem importantes para a o evangelho como um todo, mas sem a mesma clareza formal. Logo depois dos radicais estatutos econômicos, temos uma exortação contra o julgamento ao próximo $(5,1-5)$, que pode ter o objetivo de amenizar os conflitos intracomunitários que a radicalidade típica de Q poderia ocasionar. Segue-se um versículo sobre não dar o santo aos cães e não jogar pérolas aos porcos (v. 6) e outros sobre a oração (vv. 7-11), ensinando que basta pedir a Deus, que este certamente lhe dará boas dádivas. $\mathrm{O}$ versículo 12 apresenta o resumo da Lei e dos Profetas, que é fazer aos outros o 
que queremos que nos façam, e em seguida temos a famosa passagem sobre as duas portas (vv. 13-14). Chegando ao final do sermão, temos duas unidades (vv. 15-20, 21-23) que parecem formar um novo conjunto literário sobre os falsos profetas, e uma última passagem que diz que quem pratica todas essas coisas é como um homem que construiu sua casa sobre a rocha (vv. 24-27).

Parece-nos que o autor de Mateus estruturou seu sermão com começo e fim e, no meio, incorporou unidades textuais diversas, organizadas por assuntos em comum. Ele parece também ter dado prioridade aos temas acerca dos quais dispunha de mais material, por isso, após a abertura do sermão que traz o propósito existencial do grupo, insere conjuntos literários sobre a lei e as práticas religiosas, e depois outro sobre o problema da administração econômica. As unidades menores e sem materiais paralelos são colocadas depois, sem seguir qualquer padrão hierárquico, até a conclusão de 7, 24-27 e o encerramento do sermão 7, 28-29.

Enfim, podemos crer que os estatutos econômicos de 6, 19-34 estão entre os textos mais importantes do Sermão da Montanha. Vimos que no interior do sermão há alguns conjuntos literários, sendo um dos principais este em que o evangelista reuniu mais subunidades e a que dedicou maior espaço. Agora podemos prosseguir em nosso estudo para atestar o esmero com que o evangelista organizou esses estatutos econômicos.

\section{Três perícopes}

Quando abrimos uma Bíblia em Mateus 6, é comum encontrarmos os versículos de 19 a 24 agrupados sob um mesmo subtítulo. Na verdade, essas três perícopes são perfeitamente delimitáveis, mas pela pequena extensão e pela similaridade de conteúdos, acabam sendo agrupadas dessa forma pelos editores. Mostraremos uma outra razão para tratar dessas três unidades num só bloco: a similaridade formal que existe entre elas. Uma a uma, analisaremos estas três perícopes a partir da forma que lhes foi dada, acreditando que, usando esse critério com ponto de partida, encontraremos elementos característicos de Mateus que foram pouco explorados. 


\subsection{Mateus 6, 19-21}

Começando por 6, 19-21, veremos que essa perícope foi construída seguindo critérios formais típicos da poesia hebraica (LUZ, 1993, p. 498). Para sermos mais específicos, temos nesses três versículos um paralelismo antitético, ${ }^{6}$ e é principalmente esse paralelismo que vamos estudar a fim de compreender o texto a partir de suas próprias exigências estilísticas. Abaixo temos a parte "a" dos versículos 19 e 20, organizadas de modo que as semelhanças e diferenças que constituem esse paralelismo sejam destacadas:

\begin{tabular}{|l|l|l|l|}
\hline Não acumulai & tesouros & para vós & sobre a terra, \\
\hline Mas acumulai & tesouros & para vós & no céu, \\
\hline
\end{tabular}

Observando as duas frases sobrepostas, podemos ver a grande e proposital similaridade que existe entre elas. Quando, na construção de um texto, vemos que o autor se ocupou em repetir uma mesma frase duas vezes de maneira quase idêntica, nossa atenção deve voltar-se não para os pontos em comum, mas para os divergentes, onde ele cuidadosamente modificou as frases.

A função do texto acima é expressa através dos imperativos que dão início às duas frases, as quais se diferenciam apenas pela negação que antecede o primeiro imperativo. Ou seja, o texto quer transmitir duas ordens, uma para ser cumprida e outra para não ser cumprida. A segunda diferença está nos códigos topográficos "sobre a terra" e "no céu", que definem os lugares disponíveis para o acúmulo de riquezas. Os dois destinos parecem resumir toda a criação, e devem ser vistos como opostos. Céu e terra representam o certo e o errado, o transitório e o eterno, o trabalho em vão e a segurança eterna.

Passemos para a comparação das segundas partes destes mesmos versículos:

\begin{tabular}{|l|l|l|ll|}
\hline onde & traça e ferrugem destrói & e onde & ladrões arrombam e roubam; \\
\hline onde & nem traça nem ferrugem destrói & e onde & $\begin{array}{l}\text { ladrões não arrombam nem } \\
\text { roubam; }\end{array}$ & \\
\hline
\end{tabular}

O leitor ou ouvinte já ficou sabendo que não deve acumular tesouros na terra, mas o autor ainda achou necessário fornecer alguns argumentos para motivar a obediência às ordens dadas. A certeza de que a terra é um lugar inadequado para o acúmulo de bens está

\footnotetext{
${ }^{6} \mathrm{O}$ paralelismo antitético, comumente encontrado na linguagem de Jesus, caracteriza-se pela justaposição de duas frases paralelas, sendo que o sentido da segunda frase se constitui-se numa antítese ao sentido da primeira. Veja mais sobre o emprego de paralelismos no Novo Testamento em WEGNER, 1998, p. 90-92.
} 
na ação destrutiva e incontrolável da traça, da ferrugem e dos ladrões, e assim vemos na linha de cima que um dos problemas está na transitoriedade dos bens que no mundo se podem acumular. $\mathrm{O}$ argumento ainda é reforçado pelo incentivo ao acúmulo de bens no céu, onde os tesouros são incorruptíveis, imunes à ação do tempo e das pessoas malintencionadas.

Interessante observar que, no texto, Jesus afirma conhecer os tesouros celestiais, mas tais tesouros na verdade servem como uma espécie de compensador universal, um contrapeso à ausência de recompensa terrena. Como eles deviam desiludir-se em relação às riquezas naturais, veem-se de alguma forma obrigados a compensar tal desilusão com novas promessas, criando recompensas que possam servir de incentivo para as boas ações (SALDARINI, 2000, p. 152). O desejo de estar bem-posicionado socialmente é redirecionado para motivar as atitudes que o autor deseja.

Por fim, o versículo 21, que conclui a primeira perícope, traz uma sentença de efeito também formulada em duas orações paralelas:

\begin{tabular}{|l|l|}
\hline Pois onde está & o teu tesouro, \\
\hline ali estará também & o teu coração. \\
\hline
\end{tabular}

É relevante aqui que há duas ocorrências do verbo "ser/estar" (gr. eimi), uma no tempo presente e outra no futuro. Em termos de tradução não há maiores dificuldades, mas os próprios verbos nos indicam uma relação de causalidade entre as duas orações que regem; ou seja, aquilo que no presente "é", influencia diretamente aquilo que no futuro "será". Além dos verbos, relacionam-se também os seus respectivos objetos, isto é, o "tesouro" e o "coração" possuem uma estreita relação, e onde um está hoje, estará o outro no futuro. Com isso o leitor deve estar certo de que não pode adiar a decisão de mudar suas atitudes; é necessário agir agora em favor de um tesouro eterno ou no futuro ele não poderá estar no reino dos céus, já que seu tesouro sempre esteve na terra e o seu coração o acompanha.

Antes de seguirmos para a próxima perícope, gostaríamos ainda de salientar que o termo coração - que, na cultura grega, já era usado metaforicamente para se referir aos 
sentimentos de amor e afeto do ser humano, ${ }^{7}$ - usado neste texto nos mostra que inevitavelmente se está envolvido numa relação sentimental com as coisas que consideramos valiosas, e consequentemente, o acúmulo de tesouros no céu, que era apenas um investimento mais inteligente nos versículos anteriores, ganha novos sentidos. Quando alguém investe nas coisas transitórias, nos tesouros da terra, isso revela que seu coração, seus sentimentos estão neste mundo e nesta vida. Esse modo de agir, semelhante ao dos fariseus $(6,1-18)$, denuncia o homem, expõe a sua falta de fé, além de lhe trazer prejuízos.

\subsection{Mateus 6, 22-23}

Chegamos à segunda unidade desse agrupamento de textos feito pelo autor de Mateus. Mas antes de passarmos à análise do texto propriamente dito, devemos observar que esses dois versículos não possuem necessariamente um caráter econômico, embora tenhamos afirmado que de 6,19 a 34 temos uma compilação consciente de textos econômicos. Isso pode ser mais bem compreendido se nos voltarmos para o mesmo texto em seu paralelo sinótico, que encontramos em Lucas.

O texto que vimos acima - Mateus 6, 19-21 - encontra seu paralelo em Lucas 12, 33-34, mas os seguintes aparecem em Lucas 11, 34-35. No evangelho de Lucas, elas são duas perícopes bem independentes, portanto. Além da organização distinta, em Lucas, a ausência do contexto econômico leva o leitor a interpretar de forma bem diferente o texto que se refere aos olhos como a lâmpada do corpo. Para confirmar a coesão dessa compilação do conjunto textual, é necessário explicar a hermenêutica mateana, indagando os motivos que levaram o autor de Mateus a organizar assim o material que recebera da tradição.

\footnotetext{
7 Na Bíblia encontramos vários exemplos desse e de outros usos metafóricos para o coração humano. Lemos que é dele que provêm os maus desejos (Mt 15,19), que é ele que endurece quando alguém rejeita a palavra divina (Mc 16,14), e que é dele também que vem a fé. Noutro exemplo, Jesus aplica um texto de Isaías para falar dos corações distantes de Deus que possuem aqueles que se opõem a ele: "Este povo me honra com os lábios, mas o seu coração está longe de mim” (Mt 15,8).
} 


\begin{tabular}{|l|l|l|l|l|}
\hline \multicolumn{2}{|l|}{ A lâmpada do corpo é o olho: } \\
\hline Então, & se o teu olho for & simples, & o teu corpo todo será & luminoso, \\
\hline Mas & se o teu olho for & doente, & o teu corpo todo será & escuro. \\
\hline
\end{tabular}

Outra vez encontramos um paralelismo bem desenhado, mas agora ele está no centro da perícope e podemos identificar uma frase introdutória que, em linguagem metafórica, diz que o olho é o responsável pela luz interior do ser humano, e outra frase conclusiva, que salienta o terror de se ter um olho doente. A introdução é absolutamente necessária para a compreensão do texto, mas a conclusão parece ter apenas o objetivo de enfatizar o aspecto negativo do texto, dando maior ênfase à condição de escuridão daqueles que possuem um olho doente.

A disposição das duas frases paralelas nos chama a atenção para o ponto mais importante do texto: desta vez, as diferenças estão entre "simples/luminoso" e "doente/escuro". Neste ponto, devemos justificar também nossa tradução, que difere das versões mais conhecidas em dois momentos. Primeiro, temos o adjetivo "haplous", que geralmente neste texto é traduzido para o português como "bom". Porém, sabemos que há outros adjetivos mais usuais para "bom" como "agathós", e dentro do conjunto literário mateano que trata dos bens materiais, o significado primário do adjetivo, que é "simples", pareceu-nos mais apropriado. Diríamos que um olho simples é um olhar não ganancioso, que está voltado primeiramente para o tesouro celestial. É esse o tipo de olhar que iluminará o corpo todo. Depois, em função dessa primeira tradução não costumeira, também modificamos o outro adjetivo que a ele se contrapõe no paralelismo. Se usássemos "bom" no primeiro, seríamos levados a traduzir "ponerós" por "mal", seu antônimo. A estrutura do texto exige que assim seja feito. Mas como traduzimos o primeiro adjetivo por "simples", também nos vimos motivados a alterar esse por um equivalente, e achamos o adjetivo "doente" como uma possibilidade interessante.

Novamente é possível concluir, com base nas conjugações do verbo "ser/estar", que é o estado presente do olho que determina o estado futuro do corpo. Isso talvez nos indique a presença de um elemento escatológico também nessa perícope. O corpo iluminado e o corpo escuro talvez não precisem ser vistos como estados humanos, mas sim como estados do corpo humano após a irrupção futura do reino dos céus. O olho doente seria, então, uma 
expressão que se assemelha ao coração que está colocado nas coisas terrenas (v. 21), enquanto o olho simples seria semelhante ao coração voltado para as coisas celestiais. Se deveras é assim que o autor interpretou esse texto, o homem iluminado não é aquele que possui um olho simples, que se contenta no presente apenas com as coisas necessárias para sua subsistência; o homem iluminado não é, mas será o homem que possui um acúmulo de tesouros no céu. Na terra, o homem iluminado teve um olho simples, e exatamente por isso não quis acumular tesouros materiais, preferindo executar ações que lhe atribuíssem valor no céu.

\subsection{Mateus 6, 24}

Ninguém pode servir a dois senhores:

\begin{tabular}{|l|l|l|l|}
\hline Pois & ou odiará um & e amará & o outro, \\
\hline & ou se apegará a um & e se desprenderá & do outro. \\
\hline
\end{tabular}

Essa terceira perícope, formalmente, é muito parecida com a anterior. Outra vez encontramos duas frases que se relacionam através de um paralelismo, emolduradas por uma introdução e uma conclusão. Entretanto aqui há uma novidade: a introdução e a conclusão também são semelhantes formalmente e poderiam ser analisadas com um paralelismo. Isso também nos ajuda a ver que, desta vez, o clímax não está no centro, mas nas extremidades. Em resumo, o conteúdo a ser apresentado já está expresso na introdução e na conclusão: o leitor já sabe que tem que escolher entre servir a Deus e a Mamôn, e as duas frases centrais apenas enriquecem essa afirmação principal.

Os bens materiais aqui são até relacionados a ídolos através do emprego da palavra fenícia Mamôn (STEGEMANN; STEGEMANN, 2004, p. 233), e essa personificação também se apresenta no uso do verbo "servir". Quer dizer que os bens são comparados a deuses, que exigem a servidão humana, substituindo o verdadeiro Deus. A impossibilidade de se conciliar Deus e bens está expressa na conjunção “ou”, e leva o leitor à encruzilhada decisiva: ou você deixa de servir Mamôn, ou não poderá servir a Deus.

\footnotetext{
${ }^{8}$ A tradução comum das Bíblias brasileiras para essa palavra é "desprezar", todavia, por termos o verbo "katafronéo" no caso genitivo e fazendo oposição ao "antécho", que traduzimos por "apegar-se", julgamos ser esta a opção mais apropriada para traduzi-lo.
} 
É interessante notar como as duas frases do paralelismo são opostas e de forma indefinida referem-se a Deus e a Mamôn. Na primeira, os verbos são "odiará" e "amará", um negativo e outro positivo. Se você odiar Deus, amará Mamôn, e vice-versa. Na segunda frase, os verbos são invertidos, e temos "se apegará" e "se desprenderá", agora com o positivo na frente para deixar claro que estamos nos referindo à outra possibilidade.

Enfim, vemos o conjunto literário chegando a um clímax na sua radicalidade. O apelo não poderia ser mais duro, o empenho feito em busca de bens materiais implica irremediavelmente no afastamento de Deus; se os seguidores de Jesus quisessem realmente cumprir o mandamento de servir a Deus de todo o coração, teriam que substituir seus sonhos e afazeres rotineiros por aqueles que, segundo o evangelho, os aproximariam do Criador.

A sequência de três perícopes configuradas sob paralelismos só atinge seu objetivo quando as três estão reunidas. Cada uma expõe o padrão adotado para o relacionamento do cristão com os bens a seu próprio modo, e no final tem-se uma exortação completa. Sabe-se agora que não se deve acumular bens materiais, mas preferir as atitudes que somam valores ao verdadeiro tesouro do homem, que está no céu; sabe-se que somente aqueles que possuem um olho simples, livre da ganância, do materialismo, é que serão pessoas iluminadas; e por último os bens são até tratados como um ídolo que procura ocupar o lugar de senhor no coração dos homens, que pertence a Deus, em vista do que se conclui que ser independente dos laços criados pelos padrões econômicos da sociedade é estar próximo de Deus.

Mas ainda há algo a ser dito a respeito do procedimento do cristão em relação aos bens no sermão. Até aqui encontramos pequenas perícopes que exortavam o grupo mateano a não desejar riquezas, mas a aceitação desses estatutos devia ser, como ainda é hoje, recebida com certa dose de medo, de insegurança em relação ao futuro imediato neste mundo. É para amenizar essa crise que o evangelho ainda traz os versículos 25-34. 


\section{Não vos preocupeis (Mt 6, 25-34)}

Não parece difícil compreender que dos versículos 25 a 34 temos outros textos de caráter econômico reunidos neste conjunto literário que faz parte do Sermão da Montanha. No entanto, há uma diferença formal que nos faz encarar essa nova seção de outra maneira: o abandono das estruturas poéticas até aqui tão frequentes. Na verdade, temos aqui também um agrupamento de textos, provavelmente feitos pelos redatores da fonte Q, que seguem um padrão mais prosaico e sapiencial. Mesmo assim, é possível destacar algumas características formais que marcam essa nova seção e usá-las na interpretação dos textos.

\begin{tabular}{|l|l|}
\hline Introdução & Por isso vos digo: \\
\hline Não vos preocupeis... & $\begin{array}{l}\text { Não vos preocupeis com a vossa vida quanto comeis [ou quanto } \\
\text { bebeis], }{ }^{9} \text { nem com vosso corpo quanto vestis. A vida não é mais } \\
\text { que comida e o corpo que a roupa? Olhai para os pássaros do céu } \\
\text { que não semeiam e nem ceifam e nem ajuntam em celeiros, e o } \\
\text { vosso pai celeste os alimenta: vós não valeis mais do que eles? }\end{array}$ \\
\hline Qual de vós preocupando-se...? & $\begin{array}{l}\text { Ora, qual de vós preocupando-se pode acrescentar em sua idade } \\
\text { um côvado? }\end{array}$ \\
\hline Por que vos preocupais...? & $\begin{array}{l}\text { E acerca da roupa por que vos preocupais? Observai os lírios do } \\
\text { campo como crescem: não trabalham e nem fiam, e vos digo que } \\
\text { nem Salomão em toda a sua glória vestiu-se como um deles. Ora, } \\
\text { se Deus veste assim a erva do campo que hoje existe e amanhã é } \\
\text { jogada no forno, não (vestiria) muito mais a vós, (gente) de } \\
\text { pequena fé? }\end{array}$ \\
\hline
\end{tabular}

\footnotetext{
${ }^{9} \mathrm{O}$ texto de Nestlé-Aland apresenta neste ponto as palavras "= ou quanto bebeis", marcadas por um sinal que indica que este texto é omitido em parte da tradição manuscrita. Mesmo nas versões brasileiras é possível encontrar tais palavras entre colchetes, indicando a dúvida quanto à existência delas no texto original do evangelho de Mateus. O texto de Lucas, geralmente preferido para a reconstrução da versão original dos textos sinóticos em Q, também omite estas palavras em 12, 22. Se usássemos um critério formal, notaríamos que o texto fala duas vezes da vida, da comida, do corpo e das vestes, deixando sem paralelo correspondente apenas essa referência única à bebida. Isso nos levaria a omitir estas palavras; mas o possível paralelismo não nos pareceu tão evidente aqui, e como a "bebida" volta a aparecer mais adiante, esta variante não nos pareceu fator de grande importância para a leitura.

${ }^{10}$ Este "côvado" ou "cúbito" (gr. pechys) é uma unidade de medida que equivalia a aproximadamente 50 centímetros. Aqui, como se está falando da duração da vida, certamente esta unidade de medida não se refere a um espaço físico, mas metaforicamente a uma porção de tempo.
} 


\begin{tabular}{|l|l|}
\hline Não vos preocupeis... & $\begin{array}{l}\text { Portanto, não vos preocupeis dizendo: “o que comeremos?", ou } \\
\text { "o que beberemos?”, ou “o que vestiremos?” - os gentios buscam } \\
\text { justamente todas estas coisas }{ }^{11} \text { - pois vosso pai celestial sabe que } \\
\text { necessitais de todas elas. Buscai primeiro o reino dos céus e a sua } \\
\text { equidade, e todas essas coisas vos serão dadas. }\end{array}$ \\
\hline Não vos preocupeis... & $\begin{array}{l}\text { Portanto, não vos preocupeis com o amanhã, pois o amanhã se } \\
\text { preocupará com ele mesmo; basta ao dia a sua fadiga. }\end{array}$ \\
\hline
\end{tabular}

Motivados pelas conclusões alcançadas na análise das formas das perícopes anteriores, também buscamos aplicar critérios semelhantes aqui, e encontramos isto: todas as unidades que distinguimos nos quadros acima têm como ponto de partida o verbo "preocupar-se" (gr. merimnáo). Nele se encerra a mensagem central desses versículos, um incentivo ao desapego aos bens materiais feito através de argumentos que procuram convencer o cristão a não se preocupar com o dia de amanhã. Foi partindo do verbo "preocupar-se" que desmontamos este texto em pequenas subunidades e notamos que três delas repetem o refrão "não vos preocupeis...", e que estão entre as coisas que não devem causar preocupação exatamente elementos que se constituem em necessidades básicas de sobrevivência. Espera-se que Deus supra, dia a dia, a comida, a bebida e a vestimenta necessária.

Interessante é que em Mateus há destaque exatamente para a preocupação com a roupa, dentre esses elementos: a pergunta que inicia o versículo 28 (E acerca da roupa por que vos preocupais?) procura destacar que o exemplo seguinte se aplica à vestimenta. Todavia, esta pergunta não era realmente necessária, tanto que ela não existe na versão de Lucas 12, 27. Isso talvez confirme nossas suspeitas de que o problema dos bens, e em especial das roupas, é mais relevante para o evangelho de Mateus do que para os demais em função de seu contexto citadino e parcialmente elitizado, onde a recepção da tradição de Q

\footnotetext{
11 Acima, no início do versículo 31, tínhamos uma sentença conclusiva (Portanto, não vos preocupeis dizendo...) que a nosso ver devia ser seguida pelo argumento justificativo "pois o vosso pai celestial sabe que necessitais de todas elas". Assim, a tradução da conjunção grega "gar" nesta oração é determinante: se a traduzirmos da maneira mais convencional usando "pois", temos um novo argumento distinto, que justifica o pedido para não se preocupar por serem os objetos da preocupação "coisas de gentios". Além de criar um problema na sequencialidade argumentativa do texto, apresenta o hábito dos gentios de uma maneira negativa que não parece condizente com o pensamento mateano. Traduzindo a conjunção como fizemos (justamente), a oração parece mais um parêntese que não interrompe a sequencialidade do texto, e a expressão "desejos dos gentios" não se mostra pejorativa. Diríamos que os gentios, neste caso praticamente um sinônimo para as "pessoas de pequena fé" do v. 30, são aqueles que se preocupam com essas coisas necessárias que Deus voluntariamente dá aos que crêem.
} 
naturalmente causaria maiores desconfortos. Para os camponeses pobres, as vestes eram bens necessários considerados caros; para a elite citadina, as roupas eram símbolos de status superestimados, tornando-se um alvo a ser atacado pelos preceitos do protocristianismo, herdeiro da religiosidade campesina.

Pode-se resumir o conteúdo de todos esses versículos em poucas palavras: eles dizem para os cristãos obedecerem aos estatutos dos versículos 19-24 crendo na provisão divina. O que amplia a extensão dessa seção são os argumentos empregados para convencer o leitor/ouvinte de que não há motivos para preocupações. Usam-se especialmente imagens extraídas da natureza para se dizer que o trabalho constante como esperança de mudanças e segurança era combatido como atividade desnecessária.

A proposta de vida estava baseada na crença de que Deus dava mais valor aos seus servos do que aos pássaros e aos lírios, e que por isso não deixaria faltar-lhes o necessário para a sobrevivência. Além do incentivo à caridade (6,1-4), tais textos exerciam influência no desenvolvimento do trabalho missionário, na atividade dos profetas itinerantes sem pátria que seguiam o exemplo peripatético deixado desde o movimento de Jesus (THEISSEN, 2008, p. 76). No evangelho de Mateus, esses textos não só preservavam a cultura itinerante própria do primeiro cristianismo, mas também incentivaram os seguidores a suportar as limitações que lhes eram impostas pelos seus rivais. Em suma, o evangelista trabalhou para unir a tradição do evangelho radical de Q com a do evangelho narrativo de Marcos, já tentando adaptar a tradição à realidade dos sedentários urbanos que formavam esse grupo (ROLOFF, 2005, p. 186).

Para terminar nossas observações, no versículo 34 temos o substantivo "kakía", que geralmente é traduzido por "mal”. Contudo, como o tema em pauta é a preocupação com o dia de amanhã, concluímos que o texto pretende dizer que já é suficiente a preocupação com as coisas necessárias para o dia atual, e para melhor expressar esse sentido, traduzimos o substantivo por "fadiga". Embora possamos dizer que aqui alguma atividade é aceita como meio de aquisição do necessário para a sobrevivência, mesmo esse trabalho mínimo é visto com maus olhos. Parece-nos que, por voltar-se completamente para o reino dos céus, o texto menospreza tudo aquilo que com esse reino não tenha relação, como é o caso da necessidade de trabalhar para comer e vestir. 


\section{Conclusão}

Mesmo que tenhamos localizado o grupo mateano num contexto citadino, não podemos ignorar que as cidades da Palestina estavam inseridas numa sociedade essencialmente agrária, e que os textos da tradição cristã anterior a Mateus eram também frutos de grupos camponeses. Vê-se, nesses textos, a ideia de que a natureza podia produzir somente o necessário para subsistência de todos os homens, e consequentemente, se alguém possuía mais do que o necessário para a própria sobrevivência, estava acumulando riquezas de forma avarenta e provocando a escassez noutro lugar. Os ricos eram, portanto, mal vistos entre a maior parte da população e não se reconhecia qualquer mérito na aquisição das suas posses (Cf. MALINA, 2004, p. 108; STEGEMANN; STEGEMANN, 2004, p. 50). Mas as críticas às classes abastadas originárias da classe subalterna chegaram desconfortavelmente a uma das maiores cidades da Galileia por meio dos pregadores cristãos, grupo que teve origem na atividade de Jesus e de seguidores itinerantes, que haviam sido transformados pelas circunstâncias em marginais. Foi assim que esses princípios judaico-campesinos vieram ter ao coração do cristianismo mateano, e com isso mesmo a assimilação cultural típica do grupo citadino não pôde encobrir por completo o desconforto do convívio entre pessoas de diferentes classes sociais.

No evangelho de Mateus, adaptando a tradição recebida, a pobreza é primeiro uma exigência imposta pelo separatismo crescente que o grupo experimentava. Enquanto esses judeus cristãos cortam relações com os demais, suas condições financeiras sofrem consequências, e deve aceitar tal dificuldade quem pretende seguir a Jesus. Em segundo lugar, a pobreza é pregada como virtude moral com base no estilo de vida dos primeiros seguidores de Jesus. Desenvolveram-se estatutos econômicos que, embora se utilizassem de tradições anteriores, eram lidos também sob novas perspectivas, e a pauperização que os primeiros seguidores experimentaram como consequência das injustiças sociais impostas pelo império e pela elite sacerdotal (HORSLEY; SILBERMAN, 2000, p. 51) transformarase em argumento a favor da permanência dos adeptos num grupo que, aos poucos, era posto de lado pela sociedade.

Reconhecemos que exegeticamente nós demos apenas os primeiros passos nesses textos produzindo uma nova tradução e uma análise das formas, mas já se destaca a 
preocupação de Mateus com as minúcias literárias próprias da poesia hebraica, com o arranjo consciente de cada uma das perícopes que aos poucos progridem na argumentação. Nossas constatações não só fortalecem as delimitações que fizemos ao demonstrar como cada uma dessas unidades se relaciona com as outras, como também nos fornecem um caminho interpretativo para o evangelho de Mateus como um todo.

\section{Referências}

CARTER, Warren. O Evangelho de São Mateus: comentário sociopolítico e religioso a partir das margens. São Paulo: Paulus, 2002.

DUARTE, Denis. Não podeis servir a Deus e às riquezas: impactos econômicos no Evangelho de Mateus no contexto do judaísmo do Século I. 2009. Dissertação (Mestrado) Universidade Metodista de São Paulo, São Bernardo do Campo.

GARCIA, Paulo Roberto. As bem-aventuranças em Mateus: uma proposta de estrutura literária. 1995. Dissertação (Mestrado) - Universidade Metodista de São Paulo, São Bernardo do Campo.

GARCIA, Paulo Roberto. O sábado do Senhor teu Deus: o Evangelho de Mateus no espectro dos movimentos judaicos do Século I. São Bernardo do Campo: Instituto Metodista de Ensino Superior, 2001.

GARCIA, Paulo Roberto. Jesus e as tradições legais de Israel: conflitos de interpretação em torno das tradições legais no judaísmo do primeiro século. Estudos Bíblicos, Petrópolis, n. 99, p. 91-97, 2008.

HORSLEY, Richard A.; SILBERMAN, Neil Asher. A mensagem e o reino: como Jesus e Paulo deram início a uma revolução e transformaram o mundo antigo. São Paulo: Loyola, 2000.

KOESTER, H. Introdução ao Novo Testamento: v. II: História e literatura do cristianismo primitivo. São Paulo: Paulus, 2005.

LUZ, Ulrich. El Evangelio Segun San Mateo: Mt 1-7. Salamanca: Sigueme, 1993. v.1.

MALINA, Bruce J. O Evangelho social de Jesus: o reino de Deus em perspectiva mediterrânea. São Paulo: Paulus, 2004.

NESTLE, Eberhard; ALAND, Kurt. Novum Testamentum Graece. 27. ed. Stuttgart: Deutsche Bibelgesellschaft, 1993.

OVERMAN, J. Andrew. O Evangelho de Mateus e o judaísmo formativo: o mundo social da comunidade de Mateus. São Paulo: Loyola, 1997. 
ROLOFF, Jürgen. A Igreja do Novo Testamento. São Leopoldo: Sinodal, 2005.

SALDARINI, Anthony J. A comunidade judaico-cristã de Mateus. São Paulo: Paulinas, 2000.

STEGEMANN, Ekkehard W.; STEGEMANN, Wolfgang. História social do protocristianismo: os primórdios do judaísmo e as comunidades de Cristo no mundo mediterrâneo. São Paulo: Paulus, 2004.

THEISSEN, Gerd. O movimento de Jesus: história social de uma revolução de valores. São Paulo: Loyola, 2008.

WEGNER, Uwe. Exegese do Novo Testamento: manual de metodologia. São Paulo: Paulus, 1998. 